\title{
NUMERICAL ANALYSIS OF THE BEHAVIOR OF COMPRESSED THIN-WALLED ELEMENTS WITH HOLES
}

\author{
Patryk Różyło', Katarzyna Wrzesińska² \\ 1 Mechanical Engineering Faculty, Lublin University of Technology, Nadbystrzycka 36, 20-618 Lublin, Poland, \\ e-mail: p.rozylo@pollub.pl \\ 2 Faculty of Biology and Biotechnology, Maria Curie Skłodowska University, Akademicka 19, 20-033 Lublin, \\ Poland, e-mail: katarzynawrzesinska@onet.eu
}

Received: 2016.04.08

Accepted: 2016.07.04 Published: 2016.09.01

\begin{abstract}
The study investigates thin-walled steel elements in a form of openwork beams with holes described by variable geometrical parameters. The specimens are modeled numerically and additionally subjected to axial compression in order to examine the critical and post-critical behavior of the thin-walled profiles. The models of profiles are propped articulatedly on the edges of the cross-section in the upper and lower parts. The numerical analysis investigates only the problem of non-linear stability of these structures. The FEM analysis is stopped at the moment when the compressed profiles achieve the yield stress in order to determine their loss of stability without undesired strains. The numerical computations are performed using the ABAQUS ${ }^{\circledR}$ program to investigate the impact of diameter variability in the thin-walled profiles with holes under allowable operational loads. The numerical investigation was performed only with respect to elastic work, ensuring the stability of thin-walled structures.
\end{abstract}

Keywords: thin-walled structures, numerical analysis, finite element method, openwork beams, stability of thin-walled profiles.

\section{INTRODUCTION}

Openwork profiles are nowadays widely used in the building and heavy industries. The high level of reliability of these structures results from their strength properties which are higher than those of standard elements. The high demand for this type of structures is not only due to their high strength but also their higher load capacity. Thinwalled I-section profiles are nowadays more and more widely replaced by structures with holes to reduce their volume and at the same time to ensure at the same time higher load-carrying capacity and reduced stresses. The essence of contemporary thin-walled structures is that they have relatively low specific weight yet high functional and operational properties.

Thin-walled carrying structures exhibit uniquely high rigidity and strength. The main problem with steel and composite structures is stability loss, an issue widely described in numerous research publications $[1,2,5,6,8,15]$. Despite the occurrence of buckling, compressive loads can still be carried by the tested structures, even after exceeding the post-critical condition. Thinwalled profiles can be used only until they reach the yield stress. It is however impossible to restore the original shape of a structure if the elastic range has been exceeded. Elasticity is a characteristic of thin-walled structures; the elastic range ensures proper operation and usefulness of these structures $[8,21,22]$.

The design of building structures with a relatively vast useable area such as halls, storerooms and plants is predominantly based on the use of openwork beams to ensure the required strength and load capacity. One example of popular design solutions based on the use of openwork beams as load-carrying structures is shown in the below figure.

Openwork I-section beams ensure higher operational conditions due to their reduced sen- 


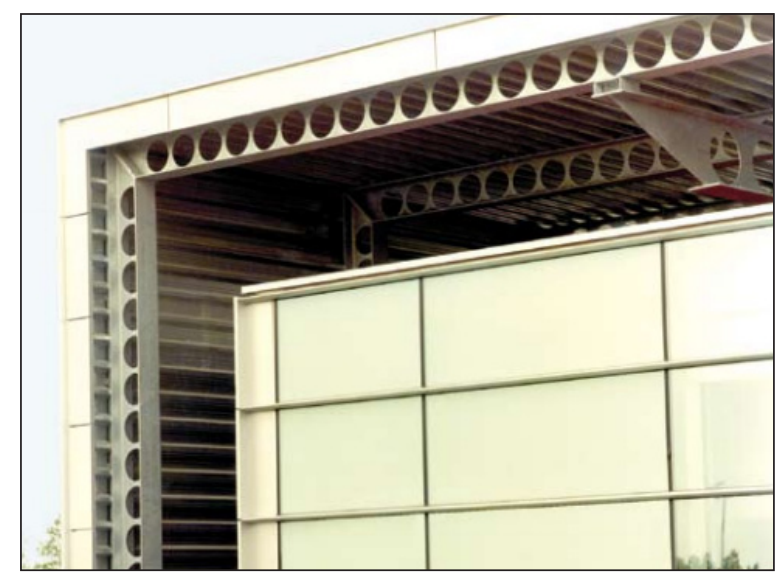

Fig. 1. Example of application for openwork beams

sitivity to very high loads resulting from specific weight and the impact of external loads. The popular methods for increasing load capacity of a structure often involve increasing the structure's specific weight due to the implemented design modifications. Nowadays, there is a demand for design solutions that ensure that a profile's weight is either similar to or - preferably - lower than the original one, and that the profile has holes with a geometry affecting the concentration of stresses and increasing its operational properties.

The problems of stability, critical and postcritical behavior have long been investigated by experts on load capacity and strength of thinwalled profiles $[2,5,8,10,16,17,20]$. The problems of stability loss and post-critical behavior of thin-walled elements with holes have been described in the publications $[6,19]$. Axial compression is a common problem in everyday operation of building structures with vast usable areas. The problem of strength of profiles exposed to axial compression becomes more serious during heavy snowfall, as snow tends to remain on the roof of a structure for a long time. It is therefore vital to make sure that carrying structures such as the tested openwork I-section profiles exhibit higher strength properties because, apart from supporting a considerable part of a structure's weight, they are additionally exposed to unfavorable weather conditions in winter. Modern design solutions such as holes described by hexagonal or - more recently - sinusoidal geometry have a positive effect on decreasing the concentration of stresses in crucial areas. Given the demand for solutions ensuring higher operational properties of structures, it is justified to scrutinize both thinwalled profiles characterized by high load-carrying capacities and carried critical loads.
This paper presents a numerical analysis of buckling, stress and displacement, as well as postbuckling states of openwork profiles with varying lengths and hole diameters.

\section{RESEARCH OBJECT AND METHODOLOGY}

The research was made for thin-walled I-section profiles with varying length and hole diameters with a constant cross section. The tested structures have been assigned the properties of constructional steel HISTAR ${ }^{\circledR} 460$ characterized by high strength, high hardness at low temperatures and excellent weldability. This innovative grade of steel has recently become popular in building industry, which provides new design opportunities for the building and engineering industries. I-section profiles made of the modern steel grade and produced by hot rolling enable erecting innovative and competitive building structures. The material properties of the discussed low-alloy steel with higher properties are listed in a table which is given below [16].

The numerical model was designed using ABAQUS ${ }^{\circledR}$. The object was modeled as a shell element with a nominal thickness of $1 \mathrm{~mm}$ (the visualization of the profile thickness was disabled during the modeling to enable further definition of the numerical problem based on the problem of nonlinear statics). The defined thickness of the shell element served for examination of the buckling of a sample profile in order to visualize the model's behavior under the defined loads. The I-section profile had normalized cross sectional dimensions [24]. In all investigated cases, the cross sections were constant. The variables solely included the diameters of the holes made in the top plate of the I-section profile. The hole diameters were changed in a range from $30 \mathrm{~mm}$ to $50 \mathrm{~mm}$, at every $10 \mathrm{~mm}$. The height of the profile's cross section was set to $80 \mathrm{~mm}$, while the length of the lower and upper plates was fixed to $46 \mathrm{~mm}$. The simulations

Table 1. Material properties of steel HISTAR ${ }^{\circledR} 460$

\begin{tabular}{|l|c|c|}
\hline \multicolumn{3}{|c|}{ Histar® 460 Steel } \\
\hline \multicolumn{1}{|c|}{ Property } & Unit & Value \\
\hline Young modulus [E] & $\mathrm{MPa}$ & 210000 \\
\hline Poisson's ratio [V] & - & 0.3 \\
\hline Yield point [Re] & $\mathrm{MPa}$ & 460 \\
\hline Yield strength [Rm] & $\mathrm{MPa}$ & 540 \\
\hline Elongation $[\mathrm{A}]$ & $\%$ & 17 \\
\hline
\end{tabular}


a)

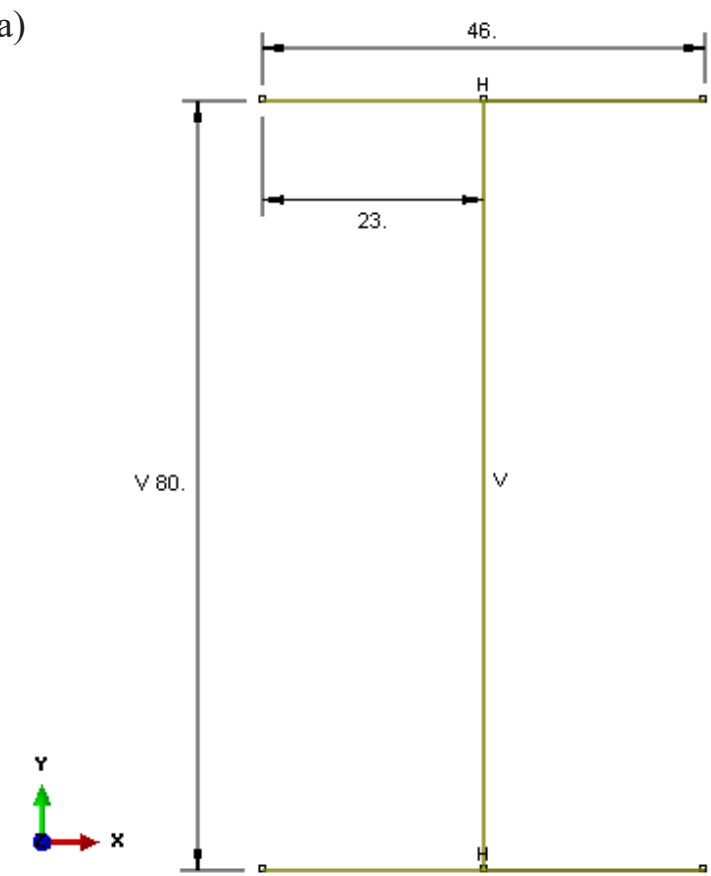

b)

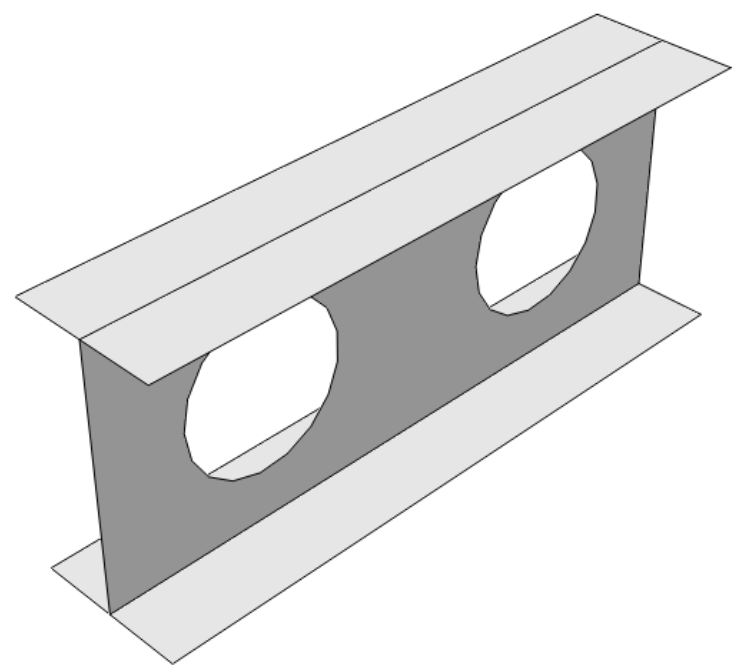

Fig. 2. Numerical model: a) cross sectional geometry of the profile, b) 3D object with a length of $200 \mathrm{~mm}$ and with holes with a diameter of $50 \mathrm{~mm}$

were performed for three cases of hole diameter variations. The ratio of diameter variations ranged between $37.5 \%$ and $62.5 \%$ relative to the constant height of the vertical profile plate. The distance between the centers of the holes was set to 100 $\mathrm{mm}$. The cross section of the structure and the 3D model of an openwork beam with holes are shown in the figure below.

The expected result of the first stage of the analysis was to obtain the first buckling mode under the defined unit load. The expected buckling mode can be produced after the application of load equal to the critical load which causes a specific form of deformation in the model. Higher buckling modes are possible due to model inaccuracies, definition of varying boundary conditions, or the occurrence of preliminary deflection.

The objective of the FEM analysis was to obtain the first buckling mode applying the ideal geometry of the model and boundary conditions. The possibility of shaping elastic properties of structures (via changing the geometry of holes in the model) is vital in terms of correct operation of objects, particularly when the application of openwork profiles depends on a specific purpose. Due to high displacements and loads, the analysis examined the numerical model's nonlinearity by the Newton-Raphson method, an iterative algorithm for determination of approximate values of elements of functions describing a given problem $[1,2]$.
The scope of the numerical computations was initially connected with the phenomenon of buckling as a part of nonlinear disturbance occurring in the process. The analysis involved obtaining visualization of the first initial buckling modes of the tested element depending on its length. The obtained buckling mode was considered in further computations related to the investigation of the post-critical state (due to the highest probability of obtaining this mode). The boundary conditions of FEM models were defined by articulated mounting in the upper and lower parts of the profile edges. Despite the three different lengths of the numerical models, the boundary conditions were identical, and the degrees of freedom were blocked to ensure correct modeling of the structure's behavior at buckling. The displacement due to load of the upper edges of the structure was uniform over the entire length of the model with a gradual increase in the defined unit load. The figure below shows the defined boundary conditions and the unit load for the FEM model of a profile with a length of $200 \mathrm{~mm}$.

To maintain proper elasticity of the element, the numerical computations were performed only until the moment when the metal exceeded its yield stress at $\mathrm{Re}=460 \mathrm{MPa}$. The load of the model shown in the above figure was applied evenly to all upper edges of the profile. A solu- 


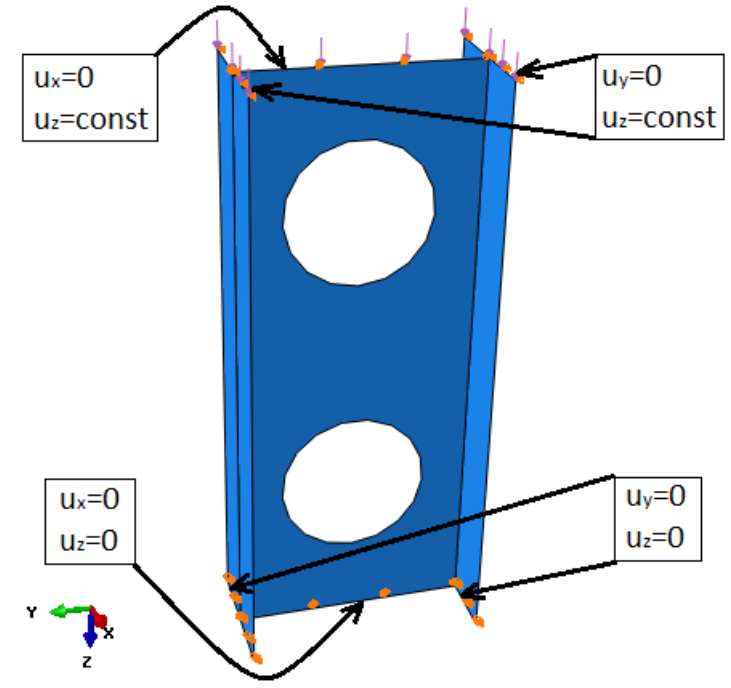

Fig. 3. Boundary conditions of the numerical model

tion of the problem of the model's behavior at critical state involved a precise definition of discretization of the numerical element. The discretization of the model was performed using four-node reduced integration shell elements, S8R, each having six degrees of freedom at every node. The discussed case involved computing a shape function of first-order finite elements. The technique of reduced integration involves removal of false modes of deforma- tion that occur in computations of higher-order polynomials to yield correct averaged results of stresses and displacements in the nodes [23]. The figure given below shows the generated finite element mesh for the tested profiles with three different lengths.

The discretization led to obtaining 1846 finite elements for the shortest profile, 4800 finite elements for the medium profile, and 9415 finite elements for the longest profile. Thereby prepared numerical models were used in a preliminary FEM analysis to obtain the buckling mode of the critical state for all tested specimens. The next stage was to determine the critical load for the tested models, for all cases of hole diameter variations. The final stage involved an analysis of the post-critical state including the geometrical imperfections caused by buckling. This stage involved the examination of displacements and stresses with respect to the critical loads determined as a result of the structure's buckling.

\section{RESULTS}

Based on the correctly defined problems of the buckling process, we determined the first modes of the critical state in the loaded profiles with a length of 200,500 and $1000 \mathrm{~mm}$, respec- a)

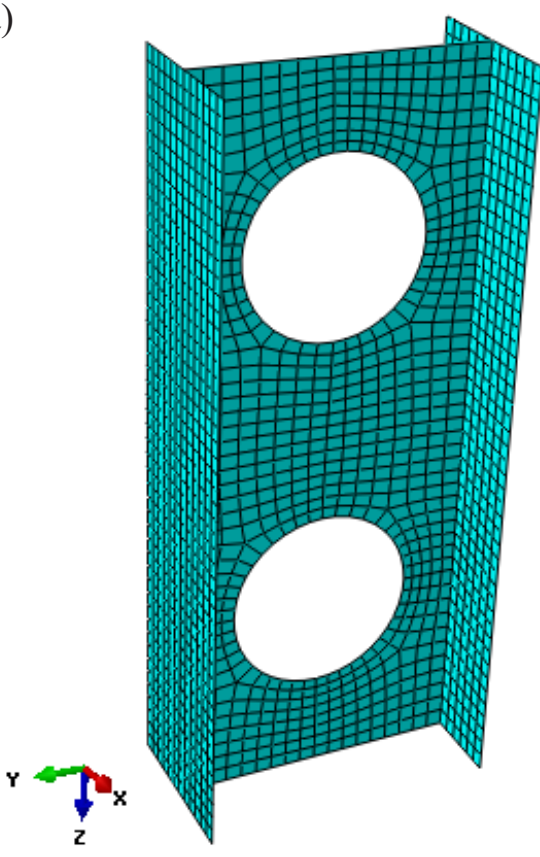

b)

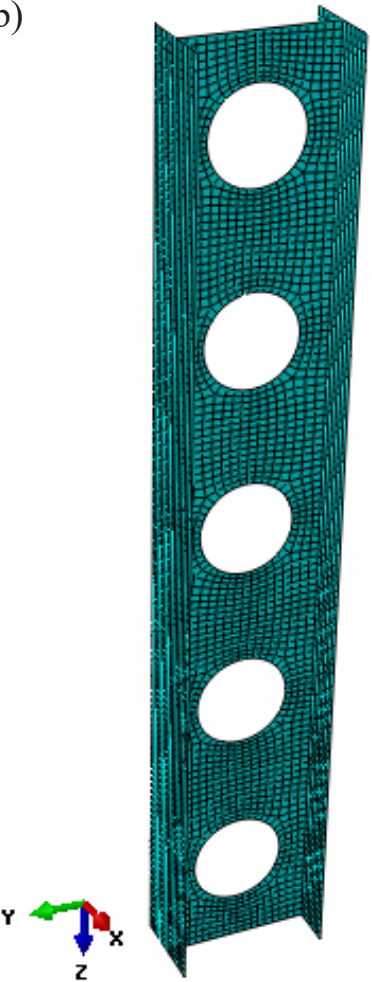

c)

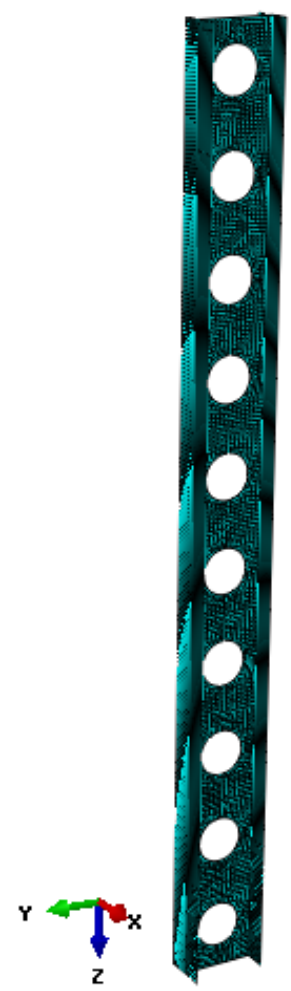

Fig. 4. Discrete model: a) profile with a length of $200 \mathrm{~mm}$, b) profile with a length of $500 \mathrm{~mm}$, c) profile with a length of $1000 \mathrm{~mm}$ 
a)

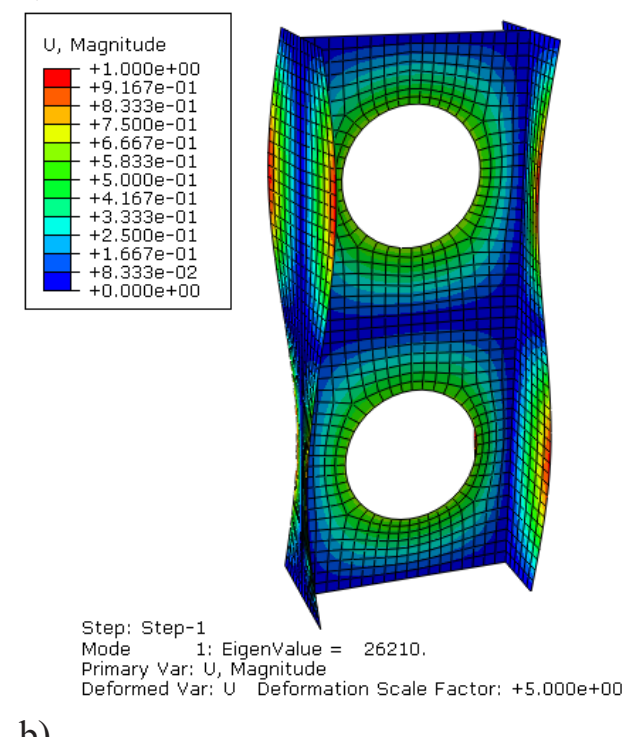

b)

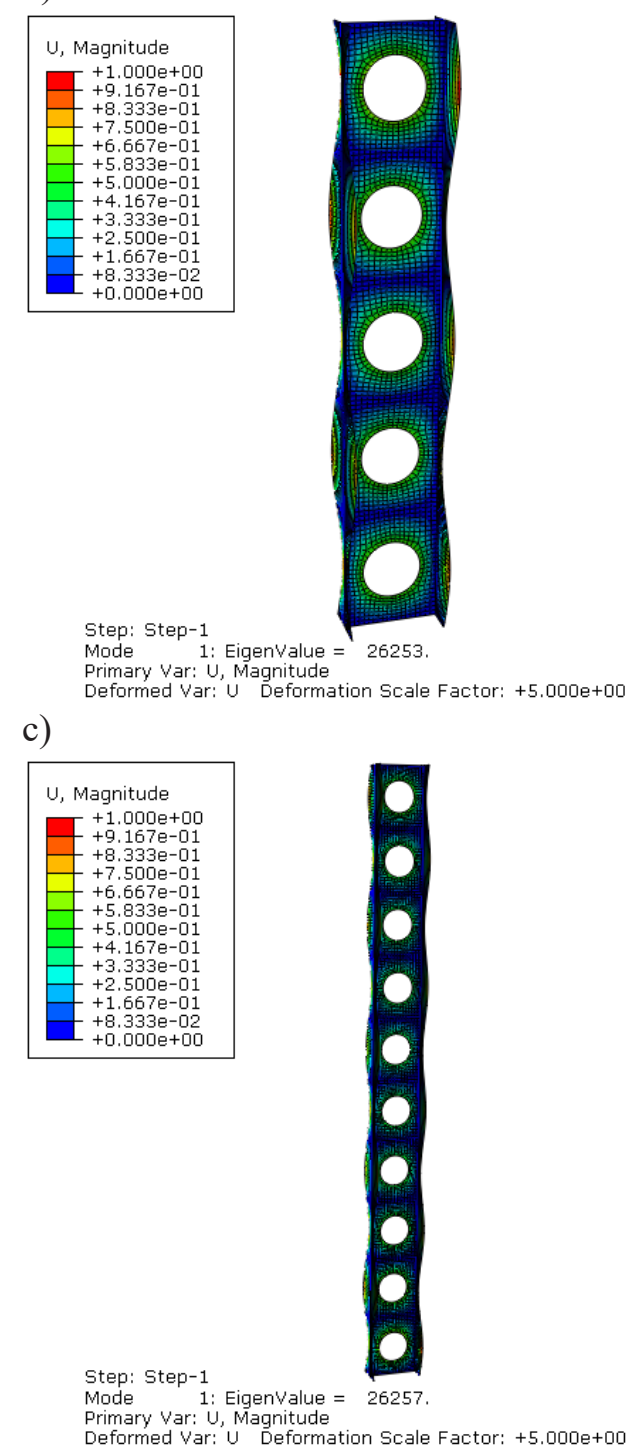

Fig. 5. Visualization of the first buckling mode:

a) profile with a length of $200 \mathrm{~mm}, \mathrm{~b}$ ) profile with a length of $500 \mathrm{~mm}, \mathrm{c}$ ) profile with a length of $1000 \mathrm{~mm}$ tively, and with $50 \mathrm{~mm}$ diameter holes spaced at regular intervals.

The FEM analysis was performed based on the first buckling mode, as this mode is the most likely to be produced due to the ideal boundary conditions and the model's geometry. The results demonstrate that the buckling mode (deformation in the form of half-waves) is the same despite the varying heights of the structures. The half-waves are located within the holes of the openwork beams. Additionally, it has been found that the critical load can amount to nearly $100 \%$, despite the varying lengths of the thin-walled I-section structures. The results demonstrate that the length of the profiles has no significant effect on the carried critical loads. The range of the carried critical loads for all profiles is between $26210 \mathrm{~N}$ and $26257 \mathrm{~N}$. Below we present the results of critical loads for the shortest profile $(200 \mathrm{~mm})$ obtained at varying diameters of the holes.

The next stage of the analysis involved determination of the effect of varying the hole diameters in a range from $30 \mathrm{~mm}$ to $50 \mathrm{~mm}$ on the carried critical loads for the other lengths. The results are listed in a table as the obtained values of the critical loads versus profile lengths and hole diameters.

The results demonstrate that the increasing of the diameter of the hole has a significant effect on the capacity of carrying higher critical loads. In addition, it is also observed that profile length does not have any significant effect on the load results. Given the binding standards and the applied structure design, the maximum diameter of holes should not be higher than $80 \%$ of the total height of the beam, while the distance between them can be reduced to the minimum [25]. The profile with a length of $200 \mathrm{~mm}$ and $30 \mathrm{~mm}$ diameter holes has a critical load of $23869 \mathrm{~N}$, while for the profile with a length of $200 \mathrm{~mm}$ and a hole diameter of $50 \mathrm{~mm}$ the load increases to $26210 \mathrm{~N}$, which is by about $10 \%$.

Table 2. Critical loads versus profile length and hole diameter

\begin{tabular}{|c|c|c|c|}
\hline & $\begin{array}{c}\text { Length }= \\
200 \mathrm{~mm}\end{array}$ & $\begin{array}{c}\text { Length }= \\
500 \mathrm{~mm}\end{array}$ & $\begin{array}{c}\text { Length }= \\
1000 \mathrm{~mm}\end{array}$ \\
\hline $\begin{array}{c}\text { Diameter }= \\
30 \mathrm{~mm}\end{array}$ & $23869 \mathrm{~N}$ & $23941 \mathrm{~N}$ & $23975 \mathrm{~N}$ \\
\hline $\begin{array}{c}\text { Diameter }= \\
40 \mathrm{~mm}\end{array}$ & $25233 \mathrm{~N}$ & $25296 \mathrm{~N}$ & $25312 \mathrm{~N}$ \\
\hline $\begin{array}{c}\text { Diameter }= \\
50 \mathrm{~mm}\end{array}$ & $26210 \mathrm{~N}$ & $26253 \mathrm{~N}$ & $26257 \mathrm{~N}$ \\
\hline
\end{tabular}


a)

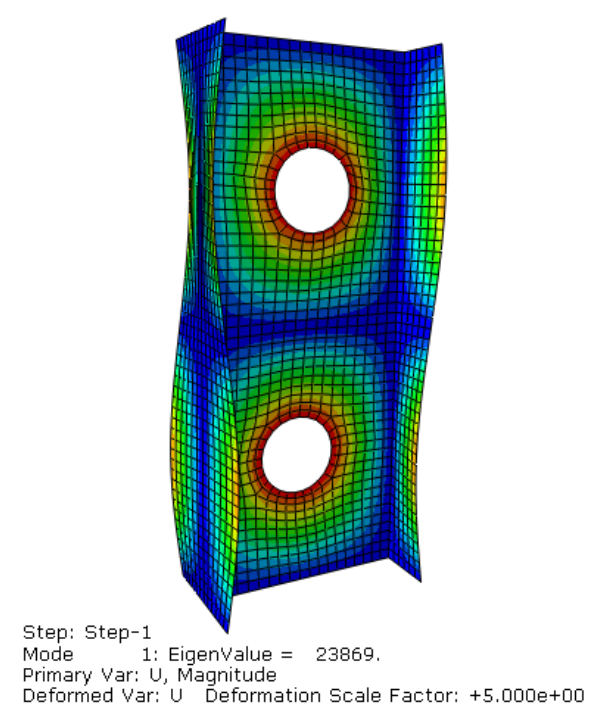

b)

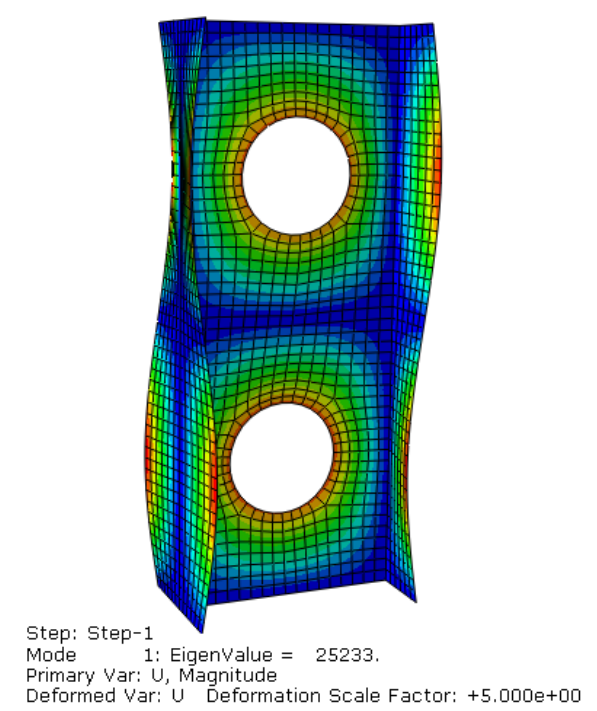

c)

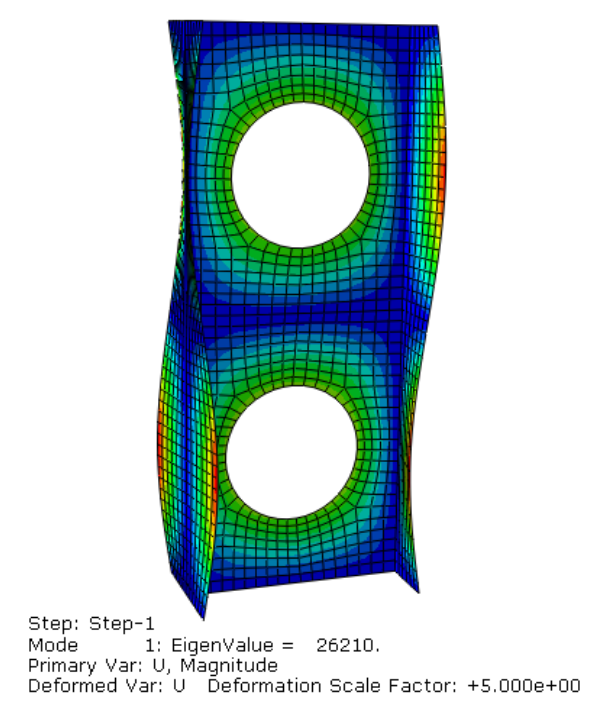

Fig. 6. Buckling mode and values of critical loads: a) $23869 \mathrm{~N}$, b) $25233 \mathrm{~N}$, c) $26210 \mathrm{~N}$
The key advantage of applying larger diameter holes in openwork profiles is that it entails reduced material volume and specific weight along with higher load capacity. The final stage of the FEM analysis was to produce results describing the post-critical behavior of the structure. The investigation of the post-critical state also involved examination of the post-critical equilibrium paths of the profiles. The results of loads and displacements enable determination of rigidity or energy consumption of the structures. The relationships describing profile deflection due to $\mathrm{Z}$-axis compression and increase in load versus deflection help describe the behavior of these structures under load until their yield point. The diagrams given below illustrate the post-critical equilibrium paths which occur at the desired length and varying diameters of the holes.

The results of the post-critical equilibrium paths describe the behavior of the profiles under the applied loads in accordance with the data given in Table 2. The compressive displacement along the $\mathrm{Z}$-axis increases proportionally to the applied load for the profiles with three different lengths. The profiles with $30 \mathrm{~mm}$ diameter holes are more rigid than the profiles with $50 \mathrm{~mm}$ diameter holes, with the latter being more energyconsuming. Depending on a demand, rigidity or energy-consumption of structures can be increased. The elastic work of the profiles, which is particularly desired for purposes of the building industry, does not exceed the yield point of the tested material. The highest concentration of stresses is spread symmetrically on the edges of the holes in each tested type of profile. The figure below illustrates the crucial spots of a $200 \mathrm{~mm}$ long profile with a $50 \mathrm{~mm}$ hole diameter after exceeding the yield point.

\section{CONCLUSIONS}

The paper presented the problem of nonlinear stability of I-section profiles subjected to axial compression. The numerical results reveal that there are similarities regarding the critical and post-critical behavior of the structures. The FEM analysis results helped determine the effect of variations in the diameter of the profile holes on the critical loads of the models depending on the applied profile height. The essence of this study was to determine the impact of height of the thin-walled I-section steel profiles on the 


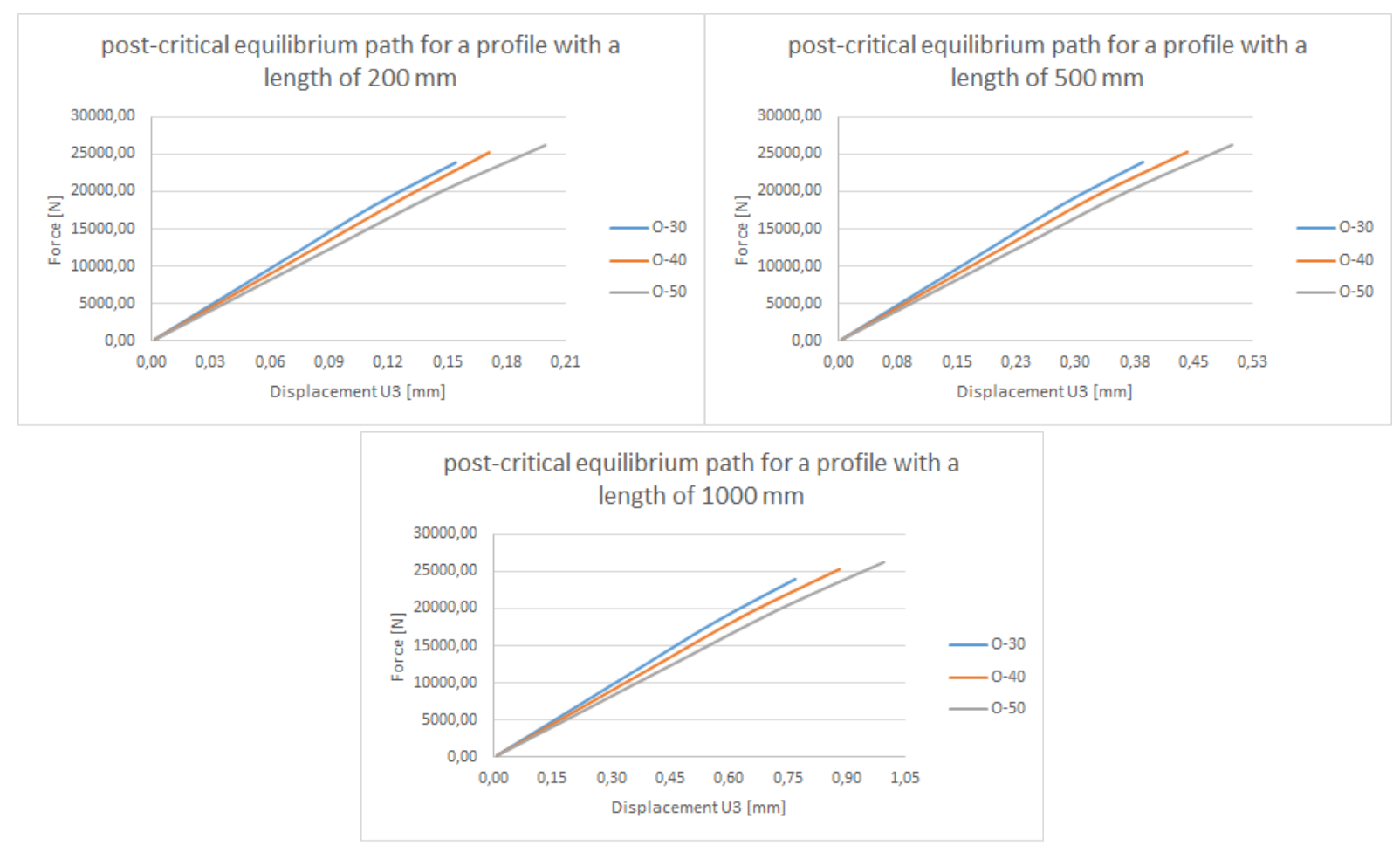

Fig. 7. Post-critical equilibrium paths versus hole diameter
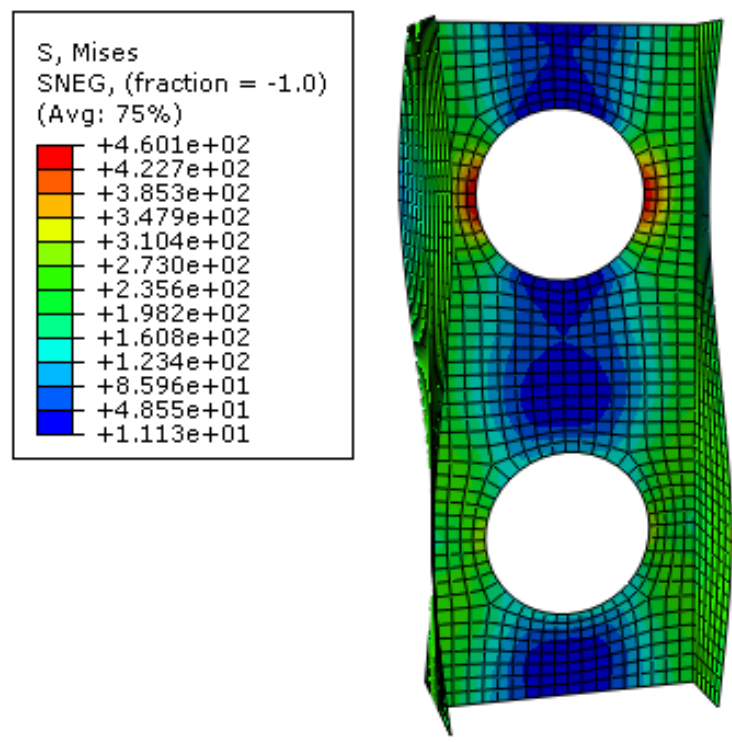

Fig. 8. Distribution of reduced stresses

carried values of critical loads, as well as the impact of the variations in diameter of the holes on load capacity of the profiles. The operational reliability of thin-walled structures can be increased thanks to adjusting the diameter of the holes, depending on whether we wish to produce profiles with higher rigidity or profiles that absorb energy generated by loads. The results led to the formulation of the following conclusions:
- height of thin-walled I-section profiles does not have a significant effect on the magnitude of critical loads,

- increase in diameter of the holes in openwork beams leads to a desired increase in the magnitude of carried critical loads,

- the buckling mode obtained in the tests has the same form of deformation for all profiles with varying heights,

- post-critical equilibrium paths of the tested structures are similar for all models despite varying heights of the profiles,

- maximum stresses described by a yield point $\mathrm{Re}=460 \mathrm{MPa}$ are concentrated near the edges of the holes,

- increase in diameter of the holes in the profiles changes the place of concentration of the highest strains.

The FEM results demonstrate vast opportunities for observation and thorough examination of deformation, as well as determination of correct operational parameters of thin-walled profiles for a full range of load. Numerical analysis is a powerful tool for investigating the load capacity and effort of thin-walled structures under defined loads. 


\section{REFERENCES}

1. Abaqus HTML Documentation.

2. Dębski H. Experimental investigation post-buckling behaviour of composite column with top-hat cross section. Eksploatacja i Niezawodnosc Maintenance and Reliability, 2, 2013, 106-110.

3. Dębski H, Koszałka G, Ferdynus M. Application of fem in the analysis of the structure of a trailer supporting frame with variable operation parameters. Eksploatacja i Niezawodnosc - Maintenance and Reliability, 14 (2), 2012, 107-114.

4. Dębski H., Rudawska A. Experimental and numerical analysis of adhesively bonded aluminium alloy sheets joints. Eksploatacja i Niezawodnosc Maintenance and Reliability, 1, 2011, 4-10.

5. Dębski H., Teter A., Kubiak T., Samborski S. Local buckling, post-buckling and collapse of thin-walled channel section composite columns subjected to quasi-static compression. Composite Structures, 136, 2016, 593-601.

6. Falkowicz K., Ferdynus M., Dębski H. Numerical analysis of compressed plates with a cut-out operating in the geometrically nonlinear range. Eksploatacja i Niezawodność - Maintenance and Reliability, 17 (2), 2015, 222-227.

7. Ferdynus M. An energy absorber in the form of a thin-walled column with square cross-section and dimples. Eksploatacja i Niezawodność - Maintenance and Reliability, 15 (3), 2013, 253-258.

8. Koiter W.T. Elastic stability and post-buckling behavior. In: Proceedings of the Symposium on Nonlinear Problems. Wisconsin: Univ. of Wisconsin Press, 1963, 257-275.

9. Kołakowski Z., Teter A. Load carrying capacity of functionally graded columns with open cross-sections under static compression. Composite Structures, 129, 2015, 1-7.

10. Kopecki T., Mazurek P. Problems of numerical bifurcation reproducing in postcritical deformation states of aircraft structures. Journal of Theoretical and Applied Mechanics, 51 (4), 2013, 969-977.

11. Królak M. and Mania R.J., (eds.), Statics, dynamics and stability of structures. Stability of thinwalled plate structures. Series of monographs. Łodz: Technical University of Lodz, 2011.

12. Lonkwic P.: Influence of friction drive lift gears construction on the length of braking distance. Chinese Journal of Mechanical Engineering, 28 (2), 2015, 363-368.

13. Lonkwic P., Różyło P.: Theoretical and experimental analysis of loading impact from the progressive gear on the lift braking distance with the use of the free fall method. Advances in Science and Technology Research Journal, 10(30), 2016, 103-109.

14. Lonkwic P., Różyło P., Dębski H. Numerical and experimental analysis of the progressive gear body with the use of finite-element method. Eksploatacja i Niezawodność - Maintenance and Reliability, 17 (4), 2015, 544-550.

15. Mania R.J., Kołakowski Z., Bienias J., Jakubczak P., Majerski K. Comparative study of FML profiles buckling and post-buckling behavior under axial loading. Composite Structures, 134, 2015, 216-225.

16. Material properties of steel, http://ds.arcelormittal. com/repo/ArcelorMittal\%20Staalhandel/Rubriek\%20Histar/Histar_EN.pdf.

17. Ritchie D., Rhodes J. Buckling and post-buckling behaviour of plates with holes. The Aeronautical Quarterly, 26 (4), 1975, 281-296.

18. Różyło P.: Optimization of I-section profile design by the finite element method. Advances in Science and Technology Research Journal, 10 (29), 2016, 52-56.

19. Shanmugam N.E. Openings in Thin-walled Steel Structures. Thin-Walled Structures, 28 (3/4), 1997, 355-372.

20. Teter A., Dębski H., Samborski S. On buckling collapse and failure analysis of thin-walled composite lipped-channel columns subjected to uniaxial compression. Thin-Walled Structures, 85, 2014, 324-331.

21. Thompson J.M.T., Hunt G.W. General theory of elastic stability. New York: Wiley, 1973.

22. Van der Heijden A.M.A. (ed.), W.T. Koiter's Elastic Stability of Solids and Structures. Cambridge University Press, 2009.

23. Zienkiewicz O.C., Taylor R.L. Finite Element Method (5th Edition) Volume 2 - Solid Mechanics. Elsevier, 2000.

24. http:/www.dziegielewski.info/Tablice/html/tabliceipe.htm (dostęp: 25.11.2015).

25.http://sections.arcelormittal.com/fileadmin/ redaction/4-Library/1-Sales_programme_Brochures/ACB/ACB_PL.pdf(dostęp: 25.11.2015). 